\title{
The Influence of Cultural Consumption Concept on Costume Design
}

\author{
Zhenghan Chen \\ Guangdong University of Science \& Technology, Dongguan 523083, China
}

Keywords: cultural concept, consumption, costume design, influence.

\begin{abstract}
In modern consumption, cultural consumption becomes a kind of fashion consumption. More and more consumers agree and follow, and the commercialization of culture and the symbolization of consumption are becoming more and more obvious. Consumers in the purchase of goods pay more attention to hidden in the commodity behind the soft commodity value, and this soft commodity value is more by the culture to bear. Then the goods will become a cultural symbol.As a social and cultural code and many consumers self-cultural packaging of essential goods, the consumption of clothing can meet the spiritual and cultural aspects of a desire.As a comprehensive cultural phenomenon, from the beginning of the process of human civilization, clothing design has its own social dimension. Since ancient times, clothing art embodies the concept of human nature at the same time, also reflects the different social and cultural and social reality.
\end{abstract}

\section{Introduction}

Fashion design is based on the premise of market consumption, consumer design center and service object for the cultural behavior, so in the fashion design behavior process, the consumer's consumption concept plays a very important role in its role. Because of the different types of consumers, a wide variety of cultural consumption concept can make the fashion design style towards the diversified direction, the popular cycle gradually shortened, emotional factors gradually strengthened. In response to these effects, the costume design should continue to explore and spread clothing brand culture into the sense of service, which can reflect the concept of innovative lifestyles. The design of clothing into the cultural connotation can guide people's cultural consumption direction.

\section{Concept of cultural consumption}

"Cultural consumption concept" is an integral part of culture, and it is a historical and cultural form. The earliest produced in Western society, and flourished in the 20th century, 30 years after the developed countries in Europe and America. After the reform and opening up, especially since the 1990s, the concept of cultural consumption has become a remarkable cultural phenomenon in contemporary China. There are many definitions of cultural consumption. One of the founders of British contemporary cultural consumption research, Williams, said: "The concept of cultural consumption is the consumer culture of all people." Mr. Yu Qiuyu, a famous contemporary writer thinks in our country: "The consumer culture that people can accept through a certain degree of counseling is Cultural consumption concept." The article refers to the concept of cultural consumption can be understood as: "A certain region or the country is generally believed by the people to accept the concept of cultural consumption. In general, the concept of cultural consumption and material life more linked. It requires easy to understand and easy to operate, easy to spread." Cultural consumption concept is the public on good or bad, gains and losses, good and evil, beauty and other specific values of the position, views, attitudes and choices. In the public value of the activities, it plays a behavior-oriented, emotional stimulation and evaluation of the role of the standard. It contains the value of the public, the pursuit of value, evaluation criteria and aesthetic taste and other aspects of the content. The Table 1 below shows the people of different ages in the purchase of clothing on all aspects of the clothing on the degree of concern. (Note: The data is from the 
Liaoning Dandong Vocational and Technical College Department of Clothing, Liaoning Dandong 118003)

Table 1: Groups of people of different ages in the purchase of clothing on all aspects of clothing attention

\begin{tabular}{|c|c|c|c|c|}
\hline project & $\begin{array}{c}\text { Under 30 years } \\
\text { old }\end{array}$ & $\begin{array}{c}31-45 \text { years } \\
\text { old }\end{array}$ & $\begin{array}{c}46-60 \text { years } \\
\text { old }\end{array}$ & $\begin{array}{c}60 \text { years old or } \\
\text { older }\end{array}$ \\
\hline Style & 26.4 & 24.6 & 24.4 & 21 \\
\hline work & 20.9 & 24.3 & 25.6 & 17.2 \\
\hline price & 20 & 23.2 & 22.5 & 30.4 \\
\hline Brand & 16.6 & 13.4 & 11 & 7.8 \\
\hline $\begin{array}{c}\text { Shopping malls } \\
\text { category }\end{array}$ & 13 & 11.2 & 12.4 & 13 \\
\hline Shopping distance & 3.1 & 3.3 & 4.1 & 10.6 \\
\hline
\end{tabular}

From the table we can see that people of different ages in the purchase of clothing on all aspects of the clothing are not the same degree of concern. Overall, the young people in the purchase of clothing consider more of the clothing style and design. The other conditions are secondary conditions. It can be seen, different age groups have different cultural consumption concept, so clothing designers need to consider the concept of cultural consumption on the impact of clothing design.

\section{The Influence of Cultural Consumption Concept on Costume Design}

\subsection{Cultural consumption concept to promote the diversification of fashion design style}

Clothing design style refers to the clothing as a commodity in kind to the consumer, including color, style, material, the external visual features, the spirit of the times, the elements of the internal cultural background and the sum of the internal culture. Diversification of fashion design style is the inevitable result of the change of cultural consumption concept. In the wave of world economic integration, the four sides of the culture of mutual absorption and integration show a colorful and flourishing culture. At the same time, the development of the economy also promotes the liberation of the mind. The consumer's personalized demand for clothing significantly enhanced the purchase of personalized clothing has become a personal means to enhance self-identity. Different personality of the consumer is in different growth background and the role of social role, and the formation of a different aesthetic standards has their own dress style. Under this influence, the fashion design field derived from different styles of different brands. Some big brands also had some different clothing style according to the different market-oriented, so as to position different sub-brand. For example, the US clothing brand Ann Taylor has LOFT, Studiond, Petites and Factory four sub-brand. It has a different brand positioning and consumer groups. In China, to Metersbonwe, for example, this "Academy" established ME \& CITY this sub-brand. Its parent brand is more high-end, with a certain purchasing power of 25 Aged 35 years' old urban white-collar workers as the target consumer groups. It focused on urban young fashion winds. From which we can draw, clothing brands or designers want to long-term high market share and win over different consumer groups, it must be committed to the consumer market segmentation and style of diversification.

\subsection{Cultural consumption concept of change to promote the popular clothing cycle shortened}

The sixties and seventies of last century, the development of China's garment industry is still slow. Clothing style, color unity, people's understanding of cultural consumption are not enough depth, which made the clothing popular period longer. Zhongshan clothing as a standard clothing for men for 30 years is a good example. However, since the reform and opening up, people's material life has been basically satisfied. The natural concern of the field of cultural consumption is getting higher and higher. Coupled with the popularity of the network, the dissemination of information provides a convenient. People can know the new information, and the acceptance of new culture is generally improved. Clothing consumption as a cultural choice related to the most intuitive and explicit activities, it naturally becomes a contemporary young People highlight the personality, which also catches up with the trend of the carrier. Fast-paced life and "cultural fast food" phenomenon. It seems 
to have affected the fashion industry and a symbol of the trend of the fashion trends from the previous two times a year to the present once a month. In addition, Xin Wei, Ruili, Mina and other fashion magazines are also popular among young women white-collar workers. On the trend of the elements of the increasing sensitivity, clothing style replacement quickly, dazzling array of clothing brands are also highly competitive. Therefore, manufacturers and designers must quickly capture the market trend, and uniquely used in fashion design, in order to stand out in many clothing brands.

\subsection{Consumers pay more attention to the inherent emotional factors to explore clothing}

Faced with the endless emergence of today's clothing brand, consumers in the selection of clothing has not only the external goods of goods as a judge to determine the quality of goods only the standard. The inherent value of clothing has become an important part of the value of clothing, with Emotional clothing goods can be more impressed by consumers. It causes its inner resonance, which is not a spiritual deep interaction, but also reflects the spirit of the consumer needs of the level of gradual improvement. In the field of costume design, many designers have also found this phenomenon. It began to try in the fashion design into the cultural value to attract consumers. For example, the "God" brand designer Liangzi in the process of designing the work of the spirit of environmental protection, the "natural, healthy" has consistently adhered to the design concept. This idea cleverly throughout the fashion design, and the human body is not hurt the hemp, cotton, silk-based, but also ingenuity to use a unique ancient Chinese and rare eco-environmental silk "scallions" as raw materials. Its The design of the apparel industry becomes a stream of clean, widely loved by young consumers. From this case can be seen, manufacturers and designers in keeping up with the trend of the same time should also focus on exploring the brand's uniqueness and content. Then it should also retain their own design and other brands of distinction in order to better clothing Community survival and development.

Since the reform and opening up, China's clothing consumer groups and the concept of cultural consumption have been constantly changing, which gives our garment industry both opportunities and challenges. On the one hand, consumers can pay more attention to "This comfortable feel is not resistant to easy to wash". This can take into more pursuit of dress decoration and aesthetics. Clothing is not just at the bottom of the theory of management, and it also needs at the bottom of the "life information". Increasingly it becomes a manifestation of personality, and it can catch up with the trend, showing the status of social symbols. This gives the costume design work more to play and imagine the space. Genegrally speaking, clothing design becomes more highlights and more artistic. On the other hand, the cultural barriers between countries, nations and regions are broken under the wave of economic integration. The foreign brands have been introduced into China. Consumer groups' awareness of world famous brands has changed quietly. Compared with local clothing Brand, it is concerned, and the Chinese consumer groups seem to be more willing to accept foreign brands. Blindly believes that the quality of foreign clothing becomes more better and more prominent social value. This blind for the domestic clothing brand is a big threat and the Chinese garment enterprises. We must analyze this issue and learn from "Li Ning" "Bosideng" and other successful out of the country's local brands of the success of the model, in order to ensure the stability of China's garment design industry healthy development.

\section{Summary}

Costume design is a kind of social culture from the sublimation of the cultural phenomenon, in the process of human civilization at different stages have different characteristics. In the new social dimension, the competition in the apparel industry is fierce, which can make the clothing manufacturers and designers to meet the public aesthetic taste. Then it can meet the mass consumer demand that has become particularly important. First of all, the concept of cultural consumption is to promote the diversification of fashion design style clothing design which refers to the clothing as a commodity presented to the consumer, including color, style, material, including external visual features and including the spirit of the times and the trend elements. Diversification of fashion design style is the inevitable result of the change of cultural consumption concept. In the wave of world 
economic integration, the four sides of the culture of mutual absorption and integration can show a colorful, flourishing culture.

\section{References}

[1] Zhang Xinke. Fashion Art Design [M]. Beijing: China Light Industry Press, 2006: 207.

[2] Xu Heng alcohol. Design aesthetics [M]. Beijing: Tsinghua University Press, 2006: 47.

[3] Chi Xiuli. After the accession to clothing consumption psychological changes and marketing strategies [J]. Fujian Textile, 2002 (08): 7-10.

[4] Yu Zuhui. "Post-quota era" China's garment industry is facing "bitter" [J]. Shopping modernization, 2005 (24): 80. 